\title{
Information Flow Management as Cornerstone for Streamlining Business Processes
}

\author{
Susanne Altendorfer-Kaiser \\ Industrial Logistics, Montanuniversitaet Leoben, Austria \\ susanne.altendorfer@unileoben.ac.at
}

\begin{abstract}
The purpose of this paper is to highlight the importance of an information flow management (IFM) and to show a way how IFM can streamline business processes. First a definition of relevant terms is given. Then the paper demonstrates how IFM can be applied to an industrial case in order to streamline and support the business processes.
\end{abstract}

Keywords: information flow, information systems, streamlining business processes, business software.

\section{Introduction}

Information flow management (IFM) and Information systems (IS) are crucial factors for companies in all lines of business. Within the years the requirements to do business have changed and got more complex. [6] Thus the companies' structures have to respond to these new situations with changing the way they are doing business. Traditional structures are no longer appropriate. New technologies and services, like location-based services, Internet of Things, Cloud Logistics and new technologies in the area of auto-ID technologies urge companies to adapt their processes and the way they do business. This change leads towards the introduction of Information flow management to optimize the effectiveness of companies. [6] Here, knowledge becomes an integral production factor. And knowledge is based on information.

This paper describes how IFM can be regarded as cornerstone for streamlining business processes. Therefore the paper sketches the value of IFM for companies described with a use case example from the automotive near industry.

\section{Terms and Definitions}

The competitiveness of companies in the future is strongly influenced by the way they do business. Here, knowledge becomes an integral production factor. And knowledge is based on information. Nowadays information is omnipresent - it is the time of the so-called information society. Not only in our private lives we are confronted with information also the daily business is formed by an information overload. Especially for companies the right information at the right time is nowadays a crucial asset. 
Barney [2] defines information as one resource (among others) that enables "the firm to conceive of and implement strategies that improve its efficiency and effectiveness". Nevertheless it is not the quantity that is important. It is the quality of information that comes into value.

In order to talk about the quality of information in general and for logistics in particular, it is important at this point to define the terms data, information and knowledge, to connect information and logistics in a more appropriate way.

- Data: The noun data is defined as facts and statistics collected together for reference or analysis. The term itself comes from the Latin plural of "datum".

- Information: For this paper the relevant definition of information is defined as something that is conveyed or represented by a particular arrangement or sequence. The term information origins in the Latin verb "informare" (in English" to inform"), which means 'to give from' or 'to form an idea of'. Furthermore the Latin noun "informatio" had already had the meaning of concept and idea".

- Knowledge: Knowledge comes from the verb "to know", which is of Germanic origin Knowledge means facts, information, and skills acquired through experience or education and can refer to theoretical and practical understanding of a subject. Furthermore it can be divided between implicit and explicit knowledge.

After having defined the terms it is furthermore relevant to bring these terms in a context, which is shown in Fig. 1.

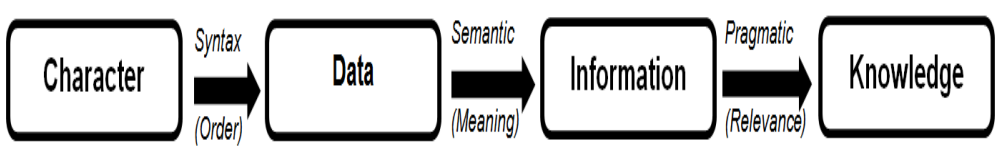

Fig. 1. Definition of the term 'information' [1]

Characters are the main element and are the smallest unit. Characters in a special form become Data. Data with a special meaning (in an appropriate context) become Information. Finally information with relevance become knowledge for someone. For example in a company's context the numbers '123456' are meaningless data (every number itself is a character). If you put e.g. Art.No. in front of the numbers Art.No.123456 - it is clearly defined what kind of information the numbers are. If this Art.No.123456 is then of relevance, for the employee dealing with it, the information become to intrinsic knowledge. At this point the employee has the knowledge what ' 123456 ' in his business context means.

Floridi defined the general definition of information (GDI) as a tripartite way: $\sigma$ is an instance of information, as semantic context, if:

- (GDI.1) $\sigma$ consists of one or more data;

- (GDI.2) the data in $\sigma$ are well-formed;

- (GDI.3) the well-formed data in $\sigma$ are meaningful [5]. 
For this definition "well-formed" means, as also shown in Figure 1, that the data are clustered together correctly, according to the syntax (order). And "meaningful" means that the data complies with the semantics (meanings). Referring to the Art.No. example, the single characters are meaningful in combination with the addendum of 'Art.No.'. And this meaningful information with relevance can then be defined as knowledge, which again is relevant for companies. Knowledge is not only relevant it is an essential factor for companies. Surveys state that the percentage of knowledge at the value creation within a company is above $60 \%$ [1]. Nevertheless, surveys also reveal that employees use more than $40 \%$ of their working time looking for the right information [1].

These circumstances lead to the necessity that an efficient information flow is necessary for every company nowadays. Out of the production point of view - as especially the production is dependent on the right information at the right time - the need for an information flow management, which can be subsumed to information logistics, comes up. Here the focus of information logistics is strongly on data and information, as shown in Fig. 2.

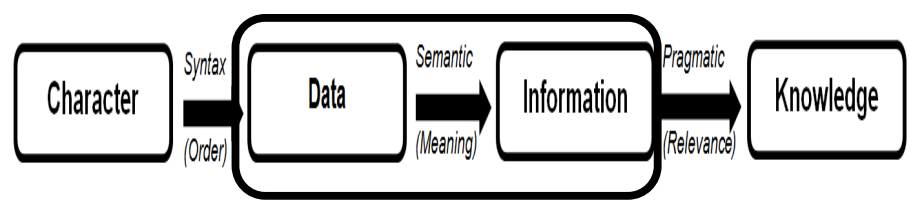

Fig. 2. Importance of the term 'information' for IFM

Especially data, its generation, storage and use in form of information is essential for the material flow. Thus the link between information and business processes can be set up.

\section{Information Flow Management}

Nowadays information is omnipresent - it is the time of the so-called information society. Especially for companies the right information at the right time is nowadays a crucial asset (That is what an efficient IFM is about). Barney [3] defines information as one resource (among others) that enables "the firm to conceive of and implement strategies that improve its efficiency and effectiveness". Nevertheless it is not the quantity that is important. It is the quality of information that comes into value. But it is not only the quality of information that matters. What's even as important is that the information is at the right time at the right place. Here the six R's of logistics matter for the proper information flow management.

The following table shows the six R's of logistics applied on information. [2] 
Table 1. 6 R's of Logistics applied on Information [2]

\begin{tabular}{|l|l|}
\hline Right Information & Necessary for the user \\
\hline Right Time & Decision-supportive \\
\hline Right Quantity & As much as necessary \\
\hline Right Place & Accessible for the user \\
\hline Right Quality & Detailed enough and usable \\
\hline Right Costs & Reasonable PRice \\
\hline
\end{tabular}

To support the realisation of an adequate IFM within the company, the concept of IT as enabler of process change is still on the forefront although dates already back to [4] and [7]. A change in information systems is possible as the technological progress over the years has opened new possibilities to support the organizational reengineering. However, information system aspects have often been left out of consideration in reengineering projects. Information systems often have had and still have the status of being a matter of course and therefore their integration is often not thoroughly considered [8]. Thus companies are far too often behind in their information technologies. Software systems are often out-dated and poorly structured. The need for agile software architecture to support IFM becomes evident when the need for more flexibility and reduced costs in the daily business urges companies to restructure.

Martin [9] defines a company as an open, socio-technical system with an organisation that has the goal to supply its customers in a satisfactorily way and by doing so making profit. As open system it has a lot of interfaces to the outside world, as shown in Fig. 3.

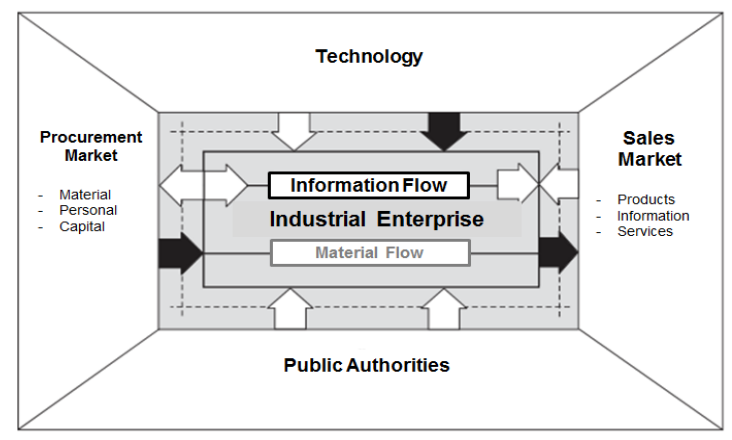

Fig. 3. Interfaces of a Company [translated to English based on [11]]

Highlighted in this figure is the information flow, which runs in parallel to the material flow. This already shows the importance of a defined information flow and a well established information flow management. And an IFM is not only necessary for intra-company flows but also for the whole supply chain. Vogt puts a lot of weight on the importance of information along the supply chain: „Information regarding the demand for, quality of the products, and other factors such as financing, and guarantees, will flow up and down the supply chain to keep every member informed of the current state of affairs pertaining to their products. This information must be timely 
and accurate as the manufacturing of the products must be adjusted to the demand as quickly as possible" [14].

This is just one statement pointing out the importance of the information flow. Thus the demand for information flow management and appropriate Information Systems is obvious. IFM has a great potential to support the processes of a company and the whole production area. Especially initiatives like "Cyber-physical Systems", "Internet of Things" and "Industry 4.0" are strongly heading in the direction of smart factory and horizontal and vertical integration along the supply chain. At this point IFM will be an essential cornerstone. And as technologies enable new software architectures, it makes sense to introduce not only standalone software systems but business software to support a proper IFM. In this context Sundblad [13] states that business software is often introduced for exactly one reason: "It should support the business and its activities to increase the productivity and efficiency of the business". The advantage of business software lies in the fact that business software can be integrated in all relevant business processes - like sales, production, after sales - to get a higher scale effect.

The following chapter will illustrate a use case where IFM - based on business software integration - is used to streamline business processes.

\section{$4 \quad$ Use Case Domain}

The research area for this use case is the automotive-near industry with a research partner that develops and sells engine test bed systems. These products are examples of automation systems. A test facility system basically measures, records, and visualizes numerous values provided by sensors according to test plans. The test facility requires appropriate parameterization for that purpose. Due to the various different use cases of test facilities, test facility systems have to be adapted according to customer-specific requirements. Typical test facilities consist of hundreds of thousands of components. According to Martyr "an engine test facility is a complex of machinery, instrumentation and support services, housed in a building adapted or built for its purpose. For such a facility to function correctly and cost-effectively, its many parts must be matched to each other while meeting the operational requirements of the user and being compliant with various regulations" [10].

A typical business process chain in the domain of this use case, shown in Fig. 4 as coarse-grained overview, covers aspects from product management, sales and order fulfillment (equal to production) to the customer service.

All processes are considered as a separate phase with several sub-processes, each having separate handover breaks and requirements.

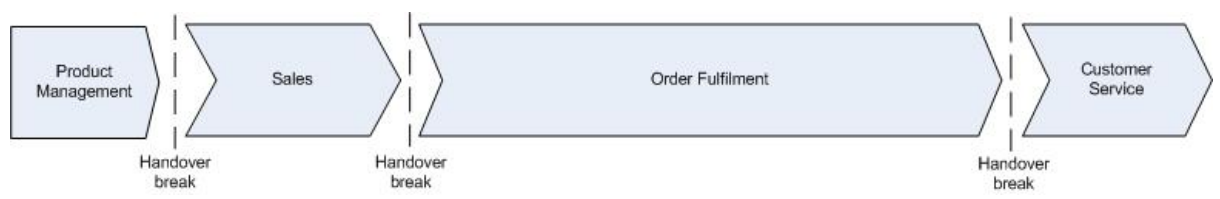

Fig. 4. Schematic Process Chain 
Taking a closer look however on the software systems in use along the process chain it becomes obvious that many different systems are used and many interfaces are needed to enable an information flow. Nevertheless all handover breaks and interfaces, even if they are automated, are a potential risk for information loss: These gaps cause a significant information loss and cause extra manual conversion and transfer efforts. Moreover relevant information might be lost throughout the process chain, and information needed in the progression of the project might not be available, as the importance of these data might not be clear upfront.

However, implementing an efficient information flow management that is supported by an integrated information system can streamline the business processes. This requires an information flow management that is implemented by integrated business software along all processes.

\section{Benefits of an IFM Approach}

Through the integration of a software system as business software, indicated as a constant banner in Fig.5, an efficient IFM can be established. Thus all essential processes will be supported and it will have predefined interfaces to other tools, which are relevant for the processes. While the new business software is the technical backbone for the information flow, the other tools, indicated as tool 1 till tool $\mathrm{n}$, are mainly used for individual matters.

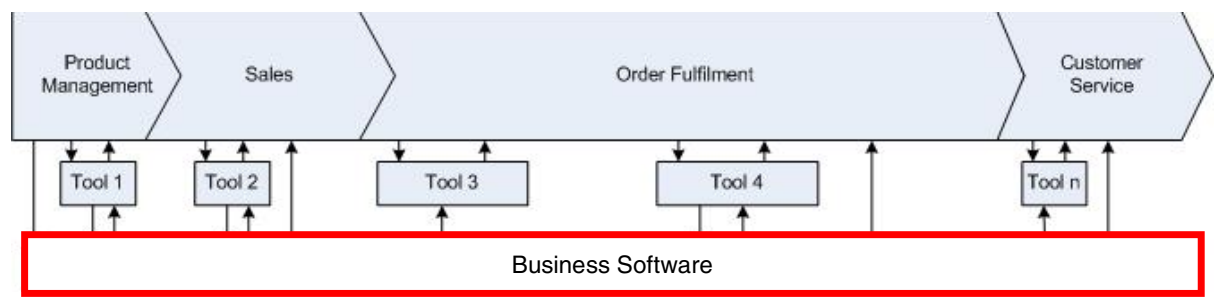

Fig. 5. IFM supported process chain

The application of this concept has individual benefits on the different processes within an organisation. Therefore all relevant information has to be added gradually to the software system. This constant information flow also enables a better fault management as the information flow is integrated along all processes.

An IFM achieves not only benefits through an integrated information flow along the processes. IFM has also effects on the processes themselves. In general there are two relevant points where first savings can be achieved:

1. a reduction of cycle times can either be achieved with an elimination of process steps or with

2. the shift of process steps to upstream processes.

The first one can be achieved, as the system offers the possibility that process steps are done automatically. The latter one enables a cost reduction as several process steps can be done earlier in the process for less costs. 


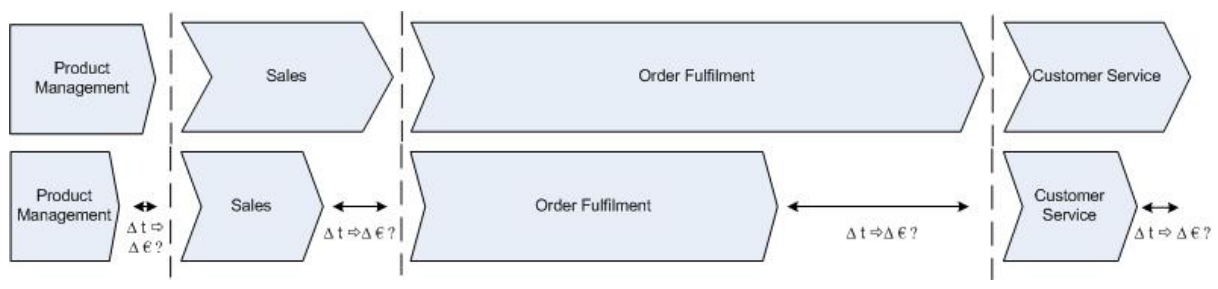

Fig. 6. Business Process Streamlining

First analyses show that savings between ten and fourteen per cent can be achieved. This first analysis, however, is only based on scenarios where the business software usage to enable IFM is mainly concentrated on the project execution phase. With a process-wide implementation, as shown in Fig. 6, even more savings can be achieved. Costs savings in a two-digit percentage range are expected.

\section{Conclusion and Future Work}

In this paper the benefits of an information flow management, realised by the use of integrated business software are described in the context of the automotive industry. It described the effects of a business software usage on the processes and on the company as a whole. Generally speaking it can be stated and also proven with first results, that an integrated business approach with IFM can have an enormous effect on the business process within an organisation. The applied research in the area of industrial automation systems proves applicable and undermines the positive effects of IFM. This approach promises to overcome information loss along the value chain and most important it supports business processes.

\section{References}

1. Auer, T.: Wissensmanagement: Reizwort oder zeitgemäße Notwendigkeit, Publikation im Controller-Leitfaden. WEKA Verlag (December 2008)

2. Augustin, S.: Informationswirtschaft und Informationslogistik im Industrieunternehmen. München (1990)

3. Barney, J.: Firm Resources and Sustained Competitive Advantage. Journal of Management 17 (1991)

4. Davenport, T.: Process Innovation: Reengineering Work Through Information Technology. Harvard Business School Press (1993)

5. Floridi, L.: Information: A Very Short Introduction, pp. 3-59. Oxford University Press (2010)

6. Hacker, W.: Informationsflussgestaltung als Arbeits- und Organisationsoptimerung. Jenseits des Wissensmanagements. vdf Hochschulverlag AG an der ETH Zürich (2007)

7. Hammer, M., Champy, J.: Reengineering the Corporation: A Manifesto for Business Revolution. Harpers Paperbacks. Rev. Upd. (2003)

8. Kawalek, J.: Rethinking Information Systems in Organizatons. Integrating Organisational Problem Solving. Routledge. New York (2008) 
9. Martin, H.: Transport-und Lagerlogistik.Planung, Struktur, Steuerung und Kosten von Systemen der Intralogistik. Springer Vieweg, München (2011)

10. Martyr, A.: Engine Testing: Theory and Practice, Butterworth Heinemann, 3rd edn (2007)

11. Osterloh, M., Frost, J.: Prozessmanagement als Kernkompetenz: Wie Sie Business Reengineering strategisch nutzen können (Processmanagement as Core Competence: How to strategically use Business Reengineering). Gabler Verlag, Wiesbaden (2006)

12. Semar, W.: Weiss + Appetito Holding AG - Software für den ganzen Konzern. In: Wölfle, R., Schubert, P. (eds.) Dauerhafter Erfolg mit Business Software - 10 Jahre Fallstudien nach der eXperience Methodik, München, pp. S.51-S.64. Carl Hanser (2009)

13. Sundblad, S., Sundblad, P.: Business Improvement through better architected software. Microsoft Architect Journal (2007)

14. Vogt, J.J., Pienaar, W., de Wit, P.W.C.: Business Logisitics Management: Theory and Practice, 2nd edn. Oxford University Press, South Africa (2005) 